\title{
A influência do setor corporativo nas discussões internacionais para o enfrentamento das mudanças climáticas
}

The influence of the corporate sector in international discussions

to tackle climate change

\section{Clara Monteiro Vieira}

Autora

claramonteirovieira@gmail.com

Graduanda em Ciências Sociais pela PUC-

Rio, bolsista PIBIC em Ciência Política.

\section{Ezequias Jagge Teixeira}

\section{Autor}

ezequias_zqui1@hotmail.com

Graduando em Ciências Sociais pela PUC-

Rio, bolsista PIBID.

\section{João Roberto Lopes Pinto}

\section{Orientador}

joaoroberto1967@gmail.com

Doutor em Ciência Política pela IUPERJ, professor no Departamento de Estudos Políticos da UNIRIO, professor no Departamento de Ciências Sociais da PUC-Rio, coordenador do Instituto Mais Democracia.

\section{Resumo}

O artigo analisa a influência de empresas nas Conferências das Partes para a ConvençãoQuadro das Nações Unidas sobre Mudanças Climáticas. Investigam-se os principais canais de participação, o poder de influência e algumas das pautas do setor privado nas conferências sobre o clima. Nota-se poderosa atuação de empresas poluidoras financiando e integrando as sessões, com propostas mais alinhadas aos seus interesses econômicos do que à causa ambiental.

Palavras-chave: Direitos humanos; UNFCCC; setor corporativo; mudanças climáticas.

\begin{abstract}
The article analyzes the influence of companies in the Conferences of the Parties to the United Nations Framework Convention on Climate Change. The main channels of participation, the power of influence and some of the private sector agendas at climate conferences are investigated. There is a powerful performance of polluting companies financing and integrating the sessions, with proposals more in line with their economic interests than with the environmental agenda.
\end{abstract}

Keywords: Human rights; UNFCCC; corporate sector; climate change 


\section{Introdução}

Toda a nossa engenharia em torno do ambiente ecologicamente equilibrado é a partir da gramática dos Direitos Humanos... Só que, hoje, se você frequenta um espaço como o da CDB, você ouve falar em "balcão de negócios de biodiversidade"'! (PARKER, 2017) ${ }^{2}$

Em um cenário marcado pelo capitalismo financeiro globalizado, o presente estudo sobre o poder das grandes corporações e seus canais de interferência sobre as demais esferas das relações políticas internacionais mostra-se de grande relevância. Em torno do tema das mudanças climáticas - assim como de toda a temática ambiental -, a influência desses setores se mostra igualmente significativa.

Por um lado, o engajamento de grandes empresas e grupos econômicos nas discussões sobre a proteção e preservação ambiental e no processo de implementação de políticas voltadas para esse propósito é de grande importância para o sucesso dessas iniciativas. Afinal, são eles uns dos principais responsáveis por imensa parte da degradação ambiental que produz efeitos nefastos percebidos no âmbito global (SULLIVAN et al., 2013). Por outro lado, encontram-se, na literatura científica, indícios de que a adesão de grandes empresas à causa ambiental, e à questão climática em particular, tende a priorizar, muitas vezes, seus próprios interesses econômicos (LEVY; EGAN, 1998, e HOFFMAN et al., 2006).

Os impactos humanitários, por vezes desastrosos, que as mudanças climáticas vêm produzindo ao redor do globo apenas reforçam a urgência desse tema. O aquecimento global acelerado dos últimos tempos vem privando milhares de pessoas ao acesso a direitos humanos fundamentais - como a vida, a segurança alimentar, a saúde e a moradia. Contudo, tais desastres não afetam todos igualmente. As principais vítimas estão frequentemente entre aqueles que menos contribuíram para o problema: povos indígenas, comunidades tradicionais, entre outros (habitantes, sobretudo, de países em via de desenvolvimento).

É a partir desse cenário injusto que despontam, no âmbito internacional, as reivindicações por justiça climática - importante pilar incorporado na Convenção-Quadro das Nações Unidas sobre Mudança Climática (UNFCCC, na sigla em inglês) -, devendo orientar as subsequentes

\footnotetext{
${ }^{1}$ CDB é a sigla para Convenção sobre Diversidade Biológica.

2 Discurso proferido por Larissa Parker na mesa sobre "Desafios da Governança Ambiental Global: Biodiversidade, Clima e Agenda 2030", do seminário "O Papel dos BRICS na Evolução da Nova Governança Ambiental”, em 2017, no Instituto de Relações Internacionais PUC-Rio. Disponível em: https://www.youtube.com/watch?v=SCTpWr1hncE. Acesso em: 6 set 2019.
} 
VIEIRA, Clara Monteiro; TEIXEIRA, Ezequias Jagge; PINTO, João Roberto Lopes. A influência do setor corporativo nas discussões internacionais para o enfrentamento das mudanças climáticas.

reuniões das Conferências das Partes signatárias dessa Convenção. Apesar disso, estudos anteriores (MORENO; SPEICH; FUHR, 2016, e CORPORATE ACCOUNTABILITY, 2017) sobre diferentes conferências ambientais apontam a tendência de uma sobreposição de interesses, nesses espaços de discussão, em favor dos setores mais poderosos política e economicamente, os quais, por sua vez, se mostram muitas das vezes empenhados na perpetuação daquela injustiça.

Este artigo tem como objetivo verificar a influência de grandes corporações nas reuniões da Conferência das Partes para a Convenção-Quadro das Nações Unidas sobre Mudanças Climáticas (COP/UNFCCC) e identificar as principais pautas de interesse desses grupos. O trabalho parte, pois, da seguinte indagação: quais os mecanismos, o peso e o rumo da atuação do setor corporativo na formação da agenda e nas decisões tomadas no interior das COPs? Para responder a essa pergunta, emprega-se uma metodologia qualitativa e quantitativa, analisandose documentos oficiais acerca do comitê e das conferências, além de textos de literatura científica e jornalística. A partir dessas fontes, procura-se responder a questões específicas como: De que modo se dá a participação do setor corporativo? Quem participa das reuniões e quantos dos participantes são representantes de grandes corporações? Quais as instituições e órgãos patrocinadores do evento? Quais as pautas defendidas pelas grandes corporaç̃es?

\section{As mudanças climáticas como pauta nas discussões internacionais}

Embora o fenômeno de mudanças climáticas não se restrinja aos tempos atuais, as transformações em curso do clima global parecem se afastar do padrão de variação verificado ao longo dos milênios. Ainda que haja polêmica quanto aos fatores que levaram ao fenômeno recentemente, especialistas ${ }^{3}$ estimam que há mais de $90 \%$ de chance de que estejam, em sua maior parte, vinculados às emissões antrópicas - ou seja, por ação humana - de gases do efeito estufa (GEE) ${ }^{4}$ (OSS, 2019).

O tema das mudanças climáticas, juntamente com a temática da crise ecológica como um todo, tornou-se importante pauta no cenário político global na segunda metade do século XX.

\footnotetext{
${ }^{3}$ Reunidos no Painel Intergovernamental sobre Mudanças Climáticas (IPCC, na sigla em inglês).

${ }^{4}$ Gases de Efeito Estufa, a cuja alta concentração na atmosfera é atribuída uma das principais causas do acelerado aquecimento global dos tempos atuais, ao exacerbar o efeito estufa - fenômeno natural que retém calor na atmosfera terrestre. São exemplos destes gases: dióxido de carbono (CO2), metano $(\mathrm{CH} 4)$, óxido nitroso (N2O), hexafluoreto de enxofre (SF6) e três grupos de gases fluorados (clorofluorcarbonos (CFCs), hidrofluorcarbonetos (HFC) e perfluorcarbonetos ou fluorocarbonetos (PFCs).
} 
VIEIRA, Clara Monteiro; TEIXEIRA, Ezequias Jagge; PINTO, João Roberto Lopes. A influência do setor corporativo nas discussões internacionais para o enfrentamento das mudanças climáticas.

No ano de 1992, representantes de diferentes países reunidos na Conferência das Nações Unidas para o Meio Ambiente e o Desenvolvimento (Rio-92) criaram a Convenção-Quadro das Nações Unidas sobre Mudança Climática (UNFCCC, na sigla em inglês). A UNFCCC é reconhecida pela Assembleia Geral das Nações Unidas como o principal fórum internacional, intergovernamental para negociar a resposta global à mudança climática (ONU Brasil, 2015). Seu propósito principal é limitar as emissões antrópicas de GEE na atmosfera.

Um aspecto central e polêmico da Convenção é o princípio das responsabilidades comuns, mas diferenciadas. Esse princípio considera a existência de capacidades e circunstâncias nacionais diferenciadas a serem relevadas na definição das contribuições exigidas de cada país. Segundo o princípio, as nações mais desenvolvidas econômica e industrialmente possuem maior responsabilidade histórica pela crise ambiental, além de apresentarem mais recursos para solucioná-la. Ademais, é verificada maior vulnerabilidade aos impactos nocivos do aquecimento global em muitos países menos desenvolvidos. A Convenção estipula, portanto, que os países desenvolvidos (reunidos no Anexo I da Convenção) ${ }^{5}$ deveriam assumir a dianteira dos esforços de enfrentamento das mudanças climáticas, bem como fornecer recursos financeiros e tecnológicos para auxiliar os países em desenvolvimento a investirem no mesmo sentido.

Os países signatários da UNFCCC são denominados "Partes" da Convenção e, desde 1995, se reúnem anualmente na Conferência das Partes (COP). Órgão supremo da ConvençãoQuadro das Nações Unidas sobre Mudança Climática, a COP tem por função traçar o encaminhamento efetivo desse tratado, adaptando-o conforme mudam as necessidades nacionais e as circunstâncias mundiais (UNCCD, 2019). Juntamente com os ministros e chefes de Estado das nações signatárias da Convenção, membros observadores também podem participar das conferências (CETESB, 2019). Durante as reuniões, que normalmente se estendem ao longo de duas semanas, os participantes examinam o estado das mudanças climáticas e debatem estratégias para proporcionar a efetiva implementação da Convenção (CETESB, 2019). As decisões apresentam um valor legal, vinculando suas metas à legislação de cada nação signatária (FERREIRA, 2010).

\footnotetext{
${ }^{5}$ O Anexo I da Convenção é composto por países europeus ocidentais (Reino Unido, França, Holanda, Bélgica, Croácia, Alemanha, Áustria, Espanha, Portugal, Dinamarca, Islândia, Itália, Grécia, Mônaco, Irlanda, Liechtenstein, Luxemburgo, Eslovênia, Suécia, Suíça, Finlândia); países industrializados do leste europeu (Polônia, República Checa, Hungria, Romênia, Eslováquia e Bulgária); países industrializados da ex-União Soviética (Rússia, Ucrânia, Estônia, Letônia e Lituânia); Estados Unidos, Canadá, Austrália, Nova Zelândia e Japão (ARAUJO, 2016).
} 


\section{Participação do setor corporativo nas COPs}

Existem duas formas de participação enquanto membros observadores na COP: via Organizações Intergovernamentais e via Organizações Não Governamentais (ONGs). É nesta última categoria que estão incluídas associações empresariais - compondo a subcategoria: Business and Industry Non-Governmental Organization (BINGOs) ${ }^{6}$. Vale acrescentar que a participação das empresas na forma de associações se dá de modo a driblar as regras de admissão de ONGs nas conferências: haja vista que é proibida a participação de instituições com fins lucrativos.

Na admissão dos membros observadores, as organizações se inscrevem sem nomear seus representantes devido à intenção do edital - não ser passível de influência por indivíduos, mas fazer sua escolha baseada numa análise das organizações propriamente ditas, segundo os critérios estabelecidos. Contudo, conforme é citado no próprio site das conferências (UNFCCC, 2019a), descobriu-se que vem acontecendo um esquema de compra individual de participação nas COPs. Com isso, organizações podem lucrar de maneira estratégica com a venda de espaços de participação para clientes, que, por sua vez, garantem seu acesso privilegiado e interessado às discussões, carregando o nome de instituições das quais não necessariamente fazem parte. Esse tipo de movimento, que, no entanto, requer investigações mais profundas, revela mais uma contradição em relação aos princípios que pautam a admissão de membros observadores.

Além da participação nas sessões enquanto membros observadores, há outras vias de atuação do setor corporativo nas conferências, a saber: organizando e integrando eventos paralelos à conferência ou relacionados a ela, também enquanto organizações observadoras (BINGOs); ou ainda patrocinando o evento - tema da penúltima seção deste artigo. A seguir, são apresentados alguns dados sobre a participação das diferentes ONGs e, em particular, das ONGs empresariais durante as sessões e os eventos paralelos à conferência.

Informações disponíveis no site oficial da UNFCCC evidenciam, desde as primeiras conferências, um crescimento expressivo do número de ONGs participando das COPs, em maiores proporções do que o aumento verificado no número de organizações intergovernamentais. O aumento do número de organizações não governamentais pode representar uma maior presença de participação advinda de canais menos burocráticos do ponto de vista estatal ou empresarial. Porém, pode também indicar que se criou uma outra porta de entrada para os interesses de cunho privado dentro das discussões climáticas. Conforme é

\footnotetext{
${ }^{6}$ Organizações Não Governamentais representando setores da Indústria e de Negócios. 
VIEIRA, Clara Monteiro; TEIXEIRA, Ezequias Jagge; PINTO, João Roberto Lopes. A influência do setor corporativo nas discussões internacionais para o enfrentamento das mudanças climáticas.

apontado em relatório do Corporate Accountability ${ }^{7}$ (2017), mesmo organizações com um histórico de enfraquecimento proposital da política climática (muitas vezes, similar aos históricos dos países onde estão sediadas), tais como a U.S. Chamber of Commerce, a Business Europe e a Business Council of Australia, podem participar das sessões enquanto membros observadores. Por mais que possam prometer total comprometimento com a agenda climática, evidências apontam no sentido contrário ${ }^{8}$.

Dentro dessa perspectiva, faz-se necessário um olhar analítico mais profundo sobre os tipos de setores circunscritos no universo das ONGs. Tomando como base o gráfico apresentado na figura 1, que retrata a percentagem de representantes na COP 22, conclui-se que os setores de organizações não governamentais mais dominantes numericamente referem-se a ENGOs (Organizações Não Governamentais Ambientais), a RINGOs (Organizações Não Governamentais de Pesquisa) e a BINGOs (Organizações Não Governamentais de Negócios e Indústria), já citados anteriormente. Enquanto esses dois últimos são responsáveis por quase 43\% dos representantes participantes da conferência, vemos, por outro lado, o número percentual de representantes indígenas em $2,2 \%$.

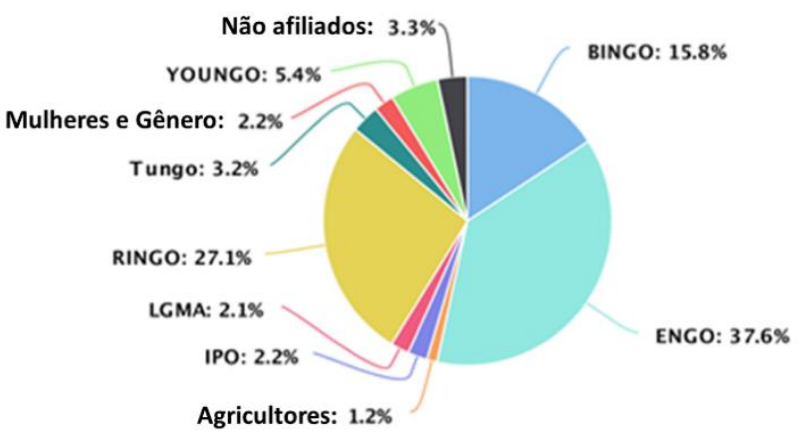

Figura 1 - Percentual de participação de representantes de ONGs por circunscrição na COP 22/CMP 12/CMA $1^{9}$

Outros dados fornecidos pelo site oficial da UNFCCC, relativos à origem regional das organizações observadoras admitidas na COP 23, assinalam grande presença $(66,8 \%)$ de

\footnotetext{
${ }^{7}$ Organização de ativistas com o intuito de fazer frente ao poder de corporações transnacionais que vêm impondo ameaças à democracia, aos direitos humanos e à vida no planeta (CORPORATE ACCOUNTABILITY, 2019).

${ }^{8}$ Durante conferência em maio de 2017, países do "Norte Global" a serviço dos interesses das grandes corporações barraram os esforços das delegações do "Sul Global" em estabelecer regras que evitassem o conflito de interesses e contivessem a influência corporativa no seio das negociações climáticas. Na mesma ocasião, manifestantes foram impedidos de usar as palavras "captura corporativa" (RUFF, 2017, e TABUCHI, 2017).

${ }^{9}$ Gráfico adaptado de (UNFCCC, 2019b)
}

DIGNIDADE RE-VISTA | ISSN2525-698X| 2018 | V. IV | N. 8 | Políticas Públicas e Direitos Humanos.

Pastoral Universitária Anchieta PUC-RIO. 
VIEIRA, Clara Monteiro; TEIXEIRA, Ezequias Jagge; PINTO, João Roberto Lopes. A influência do setor corporativo nas discussões internacionais para o enfrentamento das mudanças climáticas.

associações advindas da Europa Ocidental, da América anglo-saxã e da Oceania, a despeito do percentual baixo daquelas provenientes de outras regiões continentais.

Também com base em informações disponíveis no site oficial do comitê, desde a COP 3 (1997) até a COP 22 (2016), percebe-se uma participação expressiva das ONGs na parte organizacional dos eventos e das exposições, crescendo de modo acentuado da COP 14 para a COP 15 e da COP 20 para a COP 21. Esse crescimento pode estar associado, em ambos os casos, à grande expectativa quanto ao estabelecimento de um acordo justo e ambicioso que substituísse o Protocolo de Kyoto ${ }^{10}$. Além disso, considerando-se a participação dos diferentes tipos de ONGs na organização de eventos paralelos da COP 20 à COP 22, também se verifica a predominância das subcategorias ambientais (ENGOs), de pesquisa (RINGOs) e empresariais (BINGOs). Isso ressalta ainda mais a influência dessas subcategorias de organização não governamental na formação das agendas de discussão presentes do interior das conferências.

Em suma, os números aqui apresentados apontam para uma forte e crescente participação nas conferências sobre o clima ao longo dos anos por parte de ONGs dos setores ambientais, de pesquisa e empresariais; e um grande poder desses grupos na própria configuração dos eventos e formação da agenda de discussões. Vale acrescentar, que, segundo relatório emitido em 2017, pelo think tank InfluenceMap do Reino Unido ${ }^{11}$, empresas de energia são as lobistas mais influentes no espaço de discussão e formulação das políticas climáticas ${ }^{12}$ (KEATING, 2017b). Entre as 50 empresas mais influentes, à época da pesquisa, 35 apresentavam uma atuação contrária ao avanço das políticas climáticas, ao passo que outras buscavam dar suporte a ações climáticas que mais favorecessem seus lucros. A maioria das 35 empresas contrárias às políticas climáticas consistiam em indústrias de combustível fóssil e grandes consumidoras de energia.

\section{Pautas do setor corporativo nas reuniões}

\footnotetext{
${ }^{10}$ O protocolo de Kyoto foi aprovado na COP 3, em 1997, e vinha se mostrando, com o passar dos anos, insuficiente para reunir esforços visando o cumprimento da convenção e o efetivo enfrentamento das mudanças no clima - demandando-se a criação de um novo acordo mais ambicioso e com mais adesão das Partes. A COP 15 fracassou nesses esforços, culminando no insatisfatório Acordo de Copenhagen, que sequer chegou a ser formalmente adotado ao final das negociações (AKANLE et al., 2009); ao passo que a COP 21, mais bem-sucedida, resultou na aprovação do Acordo de Paris, atualmente em vigor.

${ }^{11}$ Organização sediada no Reino Unido neutra, independente e sem fins lucrativos que procura mapear a influência das empresas sobre as políticas climáticas.

${ }^{12}$ Esse relatório resultou de um esforço pela primeira vez empreendido em mensurar a prática do lobby no âmbito de formulação de políticas para o enfrentamento das mudanças climáticas.
}

DIGNIDADE RE-VISTA | ISSN2525-698X| 2018 | V. IV | N. 8 | Políticas Públicas e Direitos Humanos.

Pastoral Universitária Anchieta PUC-RIO. 
VIEIRA, Clara Monteiro; TEIXEIRA, Ezequias Jagge; PINTO, João Roberto Lopes. A influência do setor corporativo nas discussões internacionais para o enfrentamento das mudanças climáticas.

Compreender a atuação das grandes corporações nas Conferências das Partes da UNFCCC exige mais do que uma constatação acerca dos mecanismos e níveis de participação e do poder de influência que esses grupos têm nesses espaços de discussão. É preciso identificar quais são as principais pautas e interesses defendidos por essas corporações no decorrer das conferências. Assinalamos que este é um assunto a ser explorado com mais profundidade em trabalhos futuros; a título de ilustração, são apresentados, a seguir, alguns exemplos de pautas do setor corporativo nas reuniões da COP/UNFCCC e os respectivos agentes que as defendem. A principal base para os apontamentos feitos a seguir é o relatório do Corporate Accountability lançado em 2017 sobre a influência de grandes corporações poluidoras na COP 23.

\section{IETA e o mercado de emissões}

$\mathrm{O}$ mercado de emissões, também chamado cap and trade ${ }^{13}$, é um mecanismo de cooperação que se baseia na mesma lógica do "capitalismo verde", entendendo a mercantilização de bens comuns como uma possível solução para a crise ecológica.

Esse mecanismo estabelece um limite (cap) global de emissões de GEE, exigindo-se dos atores envolvidos obrigações de redução de emissões, que deveriam se diferenciar segundo o grau de contribuição de cada agente sobre os níveis globais de emissão (CORPORATE ACCOUNTABILITY, 2017). Definida a técnica de mensuração dos gases emitidos (segundo a métrica do carbono ${ }^{14}$ ), abre-se espaço para a comercialização (trade) de "créditos" de emissão. Esse novo sistema de mercado possibilita nações e empresas poluentes indispostas a arcar com os custos das reduções de emissões que lhes são exigidas comprarem créditos de países e grupos que contribuíram mais para essa redução.

O mecanismo de mercado foi pela primeira vez incorporado em um acordo internacional na terceira Conferência das Partes, ocorrida em Kyoto, no Japão. O Comércio de Emissões, somado a outros dois "mecanismos de compensação" 15 , concedia grande flexibilidade aos países do "Norte Global" - que mais contribuíram para a crise climática - no cumprimento de suas metas obrigatórias estabelecidas no protocolo de Kyoto. Com esses dispositivos, os países poderiam satisfazer as suas obrigações de redução de emissão de GEE sem efetivamente reduzi-

\footnotetext{
${ }^{13}$ Sistema de "limitações e comércio".

${ }^{14}$ Que considera o equivalente de uma tonelada métrica de dióxido de carbono $\left(\mathrm{CO}_{2}\right)$ como unidade base de referência para a mensuração de todos os diferentes gases de efeito estufa emitidos.

${ }^{15}$ O Mecanismo de Implementação Conjunta e o Mecanismo de Desenvolvimento Limpo, também previstos no protocolo de Kyoto.
}

DIGNIDADE RE-VISTA | ISSN2525-698X| 2018 | V. IV | N. 8 | Políticas Públicas e Direitos Humanos.

Pastoral Universitária Anchieta PUC-RIO. 
VIEIRA, Clara Monteiro; TEIXEIRA, Ezequias Jagge; PINTO, João Roberto Lopes. A influência do setor corporativo nas discussões internacionais para o enfrentamento das mudanças climáticas.

las em seus territórios por meio da compra de créditos de compensação oriundos de economias que pouco contribuíram para a crise climática e que, no entanto, acabam arcando com seus maiores custos (FERNANDES; GIRARD, 2011).

Esses mecanismos de mercado não se mostraram um método eficaz para reduzir as emissões de gases de efeito estufa no âmbito global, tampouco para promover o princípio da justiça climática. Porém, a partir da mercantilização do carbono, países puderam lucrar ou ainda evitar terem de impor regulamentações mais rigorosas sobre suas indústrias (CORPORATE ACCOUNTABILITY, 2017).

Consoante à análise de Larissa Parker (2012) sobre os riscos da lógica da "economia verde" pode-se dizer que os mercados de emissão, além de não resolverem o problema, geram novos: lucros à economia marrom e risco de especulação. É o que se verificou, por exemplo, nas experiências com o European Union Emissions Trading System (EU-ETS), sistema de mercado de emissões mais duradouro. O limite de emissões estabelecido (cap) era tão alto, que pouco esforço era exigido dos grandes poluidores, muitos dos quais ainda podiam receber licenças de emissão praticamente gratuitas e lucrar com sua venda no mercado (CORPORATE ACCOUNTABILITY, 2017).

Ademais, a ênfase na lógica mercantil como melhor saída para a crise climática também é criticada por desviar a atenção de medidas realmente necessárias para resolver o problema. Assim, transferir a responsabilidade de regulamentação de emissões às "mãos invisíveis" do mercado, além de corroborar para aumentar os lucros dos grandes poluidores, apenas prolonga e intensifica o estrago causado pelas mudanças climáticas, afetando sobretudo os que menos contribuíram para tanto (CORPORATE ACCOUNTABILITY, 2017).

Influente associação empresarial atuante nas conferências do clima, a International Emissions Trading Association (IETA) ${ }^{16}$ foi criada em 1999 para representar os grupos econômicos nas discussões sobre estratégias mercantis de resposta às mudanças climáticas, buscando minimizar "danos econômicos" nas ações climáticas (IETA, 2019). Fazem parte dessa associação grandes empresas de combustíveis fósseis (como BP e Rio Tinto, duas das fundadoras da associação), entre outros grupos econômicos que participam nos mercados globais de emissão. Em 2017, na COP 23, foi relatado que um dos então membros dessa associação empresarial, o qual também a havia presidido por numerosos anos, fazia parte da delegação do Panamá, o que lhe possibilitava acesso a espaços oficiais de discussão fechados

\footnotetext{
${ }^{16}$ Associação Internacional para o Comércio de Emissões. 
VIEIRA, Clara Monteiro; TEIXEIRA, Ezequias Jagge; PINTO, João Roberto Lopes. A influência do setor corporativo nas discussões internacionais para o enfrentamento das mudanças climáticas.

para agentes não estatais (KEATING, 2017a; SLEZAK, 2017 e CORPORATE ACCOUNTABILITY, 2017).

A atuação da International Emissions Trading Association se dá de diferentes formas (IETA, 2019):

- Participa nos espaços nacionais e internacionais da formulação e implementação de regulamentos sobre o comércio de emissões;

- Promove eventos de referência sobre esses mercados de emissões, abrindo oportunidades de networking entre os atores reunidos no evento;

- Forma coalizões, tais como com o Environmental Defense Fund (EDF), a fim de apoiar novos mercados de carbono em formação;

- Se articula com o think tank e outras instituições de pesquisa, fomentando produções acadêmicas que defendam a internacionalização dos mercados de emissão.

De acordo com relatório emitido em 2017 pela Corporate Accountability, a persistente ênfase em políticas climáticas baseadas no mercado, praticamente convertidas em "dogmas" nas conferências sobre o clima, apesar de os estudos apontarem para a sua ineficiência, representa uma das repercussões da "captura corporativa" sobre esse tema. Deve-se acrescentar que um sistema global que conecte os vários mercados nacionais de carbono - importante pauta defendida pela IETA - não foi estabelecido; porém o Acordo de Paris (definido na COP 21, em 2015) instiga as nações a expandirem seus mercados de emissão nesse sentido. O estabelecimento de vínculos entre os mercados nacionais de emissões permitiria às grandes corporações poluidoras driblar as regulamentações (impostas no âmbito nacional), como também adquirir créditos extras de emissão a fim de continuar poluindo.

\section{Climate Smart Agriculture e os gigantes do agronegócio}

Termo criado em 2010 pela Organização das Nações Unidas para Alimentação e Agricultura (FAO, na sigla em inglês), Climate Smart Agriculture (CSA) ${ }^{17}$ é um conceito vago e repleto de ambiguidades. Refere-se a uma iniciativa no seio da qual se oferecem propostas de reorientação dos sistemas agrícolas visando promover o desenvolvimento e garantir segurança alimentar em um contexto de mudanças climáticas (FAO, 2019). O termo foi pela primeira vez empregado de modo a reforçar a proposição, promovida pela FAO e pelo Banco Mundial com

\footnotetext{
17 "Agricultura Inteligente face ao Clima" ou "agricultura climaticamente inteligente". 
VIEIRA, Clara Monteiro; TEIXEIRA, Ezequias Jagge; PINTO, João Roberto Lopes. A influência do setor corporativo nas discussões internacionais para o enfrentamento das mudanças climáticas.

apoio de alguns países (Holanda, Nova Zelândia, Estados Unidos e outros), em favor de um financiamento "inteligente face ao clima" por via da mercantilização do carbono do solo (STABINSKY, 2014). Tratava-se de convencer os países em desenvolvimento a aceitar a introdução do setor da agricultura nos mercados globais de carbono.

O caráter de indefinição e vagueza do conceito de Climate Smart Agriculture abriu espaços para que grandes corporações transnacionais, empresas de fertilizantes e numerosas indústrias do agronegócio qualificassem suas atividades de "climaticamente inteligentes" (Wallmart, Monsanto, Yara international, Unilever, entre outras) (LILLISTON, 2015). Tratase de uma estratégia de greenwashing ${ }^{18}$, por meio da qual gigantes do agronegócio atribuem uma imagem ecologicamente positiva ao modelo de agricultura que implementam.

$\mathrm{Na}$ verdade, a técnica agrícola "industrializada" que sustenta o agronegócio está longe de ser benéfica ao clima. Com o predomínio da monocultura e do uso de fertilizantes sintéticos nitrogenados, por exemplo, esse modelo pode contribuir para agravar a situação climática, além de dificultar a adaptação e resiliência do solo em que se aplica diante dos impactos das mudanças climáticas (CORPORATE ACCOUNTABILITY, 2017).

Os gigantes do agronegócio, ao propor sua prática agrícola como climate smart, não se limitam a mascarar o real caráter insustentável de suas práticas agrícolas. A captura corporativa do rótulo de CSA também desvia as atenções de alternativas que poderiam, efetivamente, solucionar o problema (como a via da agroecologia) e que envolveriam mudanças mais sistêmicas, com prováveis restrições ao lucro dessas empresas, ao impor regulamentações sobre suas emissões (para além de $\mathrm{CO}_{2}$ ), por exemplo.

\section{Patrocinadores}

Como mencionado anteriormente, uma das formas de participação nas COPs é por meio do patrocínio das conferências. O pressuposto de serem organizações interessadas estritamente em combater as mudanças climáticas e promover o debate das causas ambientais por meio das conferências tem sido posto em discussão sobretudo por outras organizações, por exemplo a Corporate Accountability (2018a). Tem sido explicitado que muitos desses patrocinadores realizam ou já realizaram atividades de greenwashing, pois seus impactos ambientais estão

\footnotetext{
${ }_{18}$ Processo pelo qual empresas e outras organizações, por meio de marketing e relações públicas, atribuem a si mesmas qualidades ambientalistas, incoerentes com o caráter que assumem na prática.

DIGNIDADE RE-VISTA | ISSN2525-698X| 2018 | V. IV | N. 8 | Políticas Públicas e Direitos Humanos.

Pastoral Universitária Anchieta PUC-RIO.
} 
VIEIRA, Clara Monteiro; TEIXEIRA, Ezequias Jagge; PINTO, João Roberto Lopes. A influência do setor corporativo nas discussões internacionais para o enfrentamento das mudanças climáticas.

entre os maiores por categoria. Faz-se necessário analisar algumas dessas organizações para melhor entendermos em que termos estão postas as atividades de greenwashing.

A empresa Tauron Polska Energia S.A., uma das patrocinadoras da COP2 $4^{19}$, é a segunda maior empresa de geração de energia da Polônia e extrai a maior parte dessa eletricidade de carvão e gás. A empresa é considerada uma das mais poluidoras do ramo de extração do carvão, além de ser uma das 3 maiores empresas parte de um monopólio articulado por lobbying que abarca $80 \%$ da eletricidade da Polônia, que advém do carvão. A empresa também é responsável por 260 mortes prematuras, 70.000 dias de trabalho perdidos e custos de saúde em torno de 700 milhões de euros apenas em 2016 (CORPORATE ACCOUNTABILITY, 2018a).

A grande atividade de greenwashing feita pela empresa foi criar uma rede de compartilhamento de carros elétricos e estações de carga verdes para os participantes da COP24 e alguns locais de Katowice. Essas criações foram patrocinadas pelo ING Bank Slaski. No entanto, o detalhe disso tudo é que os carros elétricos são movidos a energia elétrica gerada a partir de carvão, o principal produto deles, com um preço elevado, algo extremamente lucrativo para a empresa e quase nada "verde". Em outras palavras, a empresa nunca teve compromisso ambiental no seu histórico e, nas atividades que demonstravam uma imagem sustentável ou preocupada com as questões ambientais, verificou-se o objetivo último do lucro. Porém, ainda assim, configurou-se como uma das patrocinadoras da conferência.

Um outro patrocinador da COP24 é o PKO Bank Polski, um dos bancos mais lucrativos da Polônia, com um lucro de mais de 724 milhões de euros só em 2017. Tal banco é fortemente engajado em financiamento de exploração de combustíveis fósseis, sobretudo petróleo e gás. Junto a outros bancos europeus, fez investimento em uma das empresas mais poluidoras da Europa, a PGE, que junto à Tauron monopoliza a geração energética da região. Não apenas essas, mas todas as empresas de carvão e gás, mesmo as grandes estatais, estão sob os investimentos do banco. Em outras palavras, o PKO Bank Polski, um dos mais fortes patrocinadores da COP24, é também um dos patrocinadores do movimento predatório da exploração de combustíveis fósseis, que é responsável por grandes impactos ambientais não revertidos (CORPORATE ACCOUNTABILITY, 2018a).

Além de funcionar como estratégia de greenwashing, o patrocínio também pode servir como mecanismo de compra de acesso ao espaço de negociações das conferências climáticas (CORPORATE ACCOUNTABILITY, 2018b). Uma vez envolvendo grandes poluidores como

\footnotetext{
${ }^{19}$ As patrocinadoras da COP 24 incluíam: Tauron, JSW, PGE, PZU, PKO Bank, PGNiG, Grupa LOTOS S.A, PKN Orlen. 
VIEIRA, Clara Monteiro; TEIXEIRA, Ezequias Jagge; PINTO, João Roberto Lopes. A influência do setor corporativo nas discussões internacionais para o enfrentamento das mudanças climáticas.

patrocinadores, é previsível que se acentue o conflito de interesses no debate conduzido no interior das conferências.

\section{Conclusão}

Este trabalho procurou investigar sobre os principais canais de participação, o poder de influência e algumas das pautas do setor empresarial nas conferências sobre o clima.

Observou-se que, de modo a driblar as regras que proíbem a participação de instituições com fins lucrativos como membros observadores durante as sessões, corporações podem se fazer representar na forma de associações empresariais (BINGOs). Assim, também podem participar da organização da agenda de discussões e de eventos paralelos às conferências. Ademais, revela-se como o patrocínio representa outro poderoso mecanismo de influência das firmas, ao lhes permitir acesso privilegiado aos fóruns e ainda fortalecer seu poder de lobby, na medida em que atribuem uma imagem "verde" à companhia, ocultando o caráter verdadeiramente degradante que na prática assumem (greenwashing).

O estudo assinala a considerável (e crescente) presença de organizações não governamentais (sobretudo dos setores ambientais, de pesquisa e empresariais) nas sessões, no decorrer das diferentes COPs, em especial naquelas conferências em que se esperava a aprovação de grandes acordos (como o Acordo de Copenhagen, na COP 15, e o Acordo de Paris, na COP 21). Verificou-se, no entanto, uma influência desigual das diferentes categorias de ONGs e, em certa medida, contraditória com o propósito das reuniões. Entre os agentes privados mais influentes nesses eventos estão muitas empresas que lucraram com os danos sobre o clima, ao passo que setores da sociedade civil menos responsáveis e, entretanto, mais afetados pelas mudanças climáticas tendem a apresentar influência marginal nos processos decisórios.

Por sua vez, as pautas empresariais assinaladas neste estudo - a defesa do agronegócio e a defesa do mecanismo de mercado como melhores saídas para o problema climático evidenciam tentativas de evitar as regulamentações sobre as empresas poluidoras, bem como de mascarar o caráter degradante de suas práticas. Acima de tudo, revelam-se esforços para desviar a atenção de soluções efetivas, centradas no meio ambiente enquanto direito humano, as quais poriam em xeque o poder econômico dessas grandes corporações, tais como o manejo coletivo dos bens comuns e a opção pela agroecologia. 
VIEIRA, Clara Monteiro; TEIXEIRA, Ezequias Jagge; PINTO, João Roberto Lopes. A influência do setor corporativo nas discussões internacionais para o enfrentamento das mudanças climáticas.

Em suma, percebe-se um esforço constante das empresas privadas, via associações empresariais ou patrocínio, em aderir ao pacote de sustentabilidade relacionado ao Acordo de Paris. Contudo, na maioria dos casos analisados neste trabalho, esse esforço aparece pautado em objetivos bem explícitos voltados ao mercado e menos em preocupações propriamente ecológicas. Apontam para essa postura a expressiva e influente participação nas conferências climáticas por parte de empresas com práticas socioambientais devastadoras, apresentando propostas, muitas vezes, que pouco ou nada contribuem para a efetiva proteção dos direitos sociais e ambientais ameaçados pelas transformações climáticas em curso.

Os resultados do nosso trabalho apontam para a perpetuação de uma tendência que trabalhos anteriores (LEVY; EGAN, 1998, HOFFMAN et al., 2006, e FERNANDES; GIRARD, 2011) já haviam constatado. Observa-se uma crescente adesão das estratégias políticas e econômicas de grandes corporações à agenda de enfrentamento das mudanças climáticas, mas em condições específicas - buscando evitar iniciativas radicais que limitem seus lucros ou thes imponham regulações extensivas.

Este estudo reitera, ainda, a expressiva influência que essas grandes empresas apresentam sobre as negociações na principal conferência intergovernamental sobre mudanças climáticas. Desse modo, revela a importância de uma investigação mais profunda acerca das influências e pautas de grandes corporações na definição das políticas climáticas no âmbito internacional. 


\section{Referências bibliográficas}

AKANLE, T. et al. Summary of the Copenhagen Climate Change Conference. Earth Negotiations Bulletin, dez 2009. Disponível em: https://enb.iisd.org/vol12/enb12459e.html. Acesso em: 6 set 2019.

ARAUjO, A. C. P. Como comercializar créditos de carbono. São Paulo: Trevisan Editora Universitária, 2006.

CETESB. Conferência das Partes (COP). Disponível em: https://cetesb.sp.gov.br/proclima/conferencia-das-partes-cop/. Acesso em: 6 set 2019.

CORPORATE ACCOUNTABILITY. Polluting Paris: How Big Polluters are undermining global climate policy, nov 2017. Disponível em: https://www.corporateaccountability.org/resources/polluting-paris-big-polluters-underminingglobal-climate-policy/. Acesso em: 5 ago 2019.

. Factfile: COP 24 corporate sponsors, dez 2018a. Disponível em: https://www.corporateaccountability.org/wp-content/uploads/2018/12/COP24-Factfile.pdf. Acesso em: 28 jun 2019.

Statement: Polish coal corporation JSW first official COP24 sponsor, 27 nov 2018b. Disponível em: https://www.corporateaccountability.org/media/statement-polish-coalcorporation-jsw-first-official-cop24-sponsor/. Acesso em: 6 set 2019.

Who we are. Disponível em: https://www.corporateaccountability.org/who-we-are/. Acesso em: 12 set 2019.

FAO. Climate-Smart Agriculture. Disponível em: http://www.fao.org/climate-smartagriculture/en/. Acesso em: 6 set 2019.

FERNANDES, S.; GIRARD, R. Corporations, climate and the United Nations: how big business has seized control of global climate negotiations. Polaris Institute, 2011. Disponível em: http://www.polarisinstitute.org/corporations_climate_and_the_un. Acesso em: 14 out 2019.

FERREIRA, L. Entenda a COP: perguntas e respostas sobre a Conferência do Clima. UOL Ciência e Saúde, 27 nov 2010. Disponível em https://noticias.uol.com.br/ciencia/ultimasnoticias/redacao/2010/11/27/entenda-a-cop-perguntas-e-respostas-sobre-a-conferencia-doclima.htm. Acesso em: 6 set 2019.

HOFFMAN, A. J. et al. Getting Ahead of the Curve: Corporate Strategies That Address Climate Change. Pew Center on Global Climate Change, 2006.

INTERNATIONAL EMISSIONS TRADING ASSOCIATION (IETA). Our Mission. Disponível em: https://www.ieta.org/Our-Mission. Acesso em: 6 set 2019.

KEATING, D. COP23: Corporations and lobbyists welcome in Bonn. Deutsche Welle, 10 nov 
VIEIRA, Clara Monteiro; TEIXEIRA, Ezequias Jagge; PINTO, João Roberto Lopes. A influência do setor corporativo nas discussões internacionais para o enfrentamento das mudanças climáticas.

2017a. Disponível em: https://www.dw.com/en/cop23-corporations-and-lobbyists-welcomein-bonn/a-41331538. Acesso em: 6 set 2019.

Koch Brothers and ExxonMobil are most influential climate lobbyists - report. Deutsche Welle, 2017b. Disponível em: https://www.dw.com/en/koch-brothers-andexxonmobil-are-most-influential-climate-lobbyists-report/a-40510038. Acesso em: 6 set 2019.

LEVY, D. L.; EGAN, D. Capital Contests: National and Transnational Channels of Corporate Influence on the Climate Change Negotiations. Politics \& Society, v.XXVI, n.3, p.337-61, set 1998.

LILLISTON, B. The clever ambiguity of climate smart agriculture. IATP, $4 \mathrm{dez} 2015$. Disponível em: https://www.iatp.org/blog/201812/clever-ambiguity-climate-smart-agriculture. Acesso em: 6 set 2019.

MORENO, C.; SPEICH, D.; FUHR, L. A Métrica do Carbono: abstrações globais e epistemicídio ecológico. Rio de Janeiro: Fundação Heinrich Böll, 2016.

ONU Brasil. Agenda 2030. 13 out 2015. Disponível em: https://nacoesunidas.org/pos2015/agenda2030/. Acesso em: 6 set 2019.

OSS. Global Warming Natural Cycle. Disponível em: http://ossfoundation.us/projects/environment/global-warming/natural-cycle. Acesso em 6 set 2019.

PARKER, L. Capitalismo "Verde": como os novos mecanismos jurídicos e financeiros preparam o mercado para a economia. In: FUNDAÇÃO BOELL. Um Campeão Visto de Dentro: Uma Análise do Modelo de Desenvolvimento Brasileiro. Rio de Janeiro: Fundação BOELL, 2012.

RUFF, K. Climate change: UN fails to address industry influence. The BMJ Opinion, 21 jul 2017. Disponível em: https://blogs.bmj.com/bmj/2017/07/21/kathleen-ruff-climate-change-unfails-to-address-industry-influence/. Acesso em: 6 set 2019.

SLEZAK, M. Fossil fuel companies undermining Paris agreement negotiations: report. The Guardian, 12 nov 2017.2 Disponível https://www.theguardian.com/environment/2017/nov/01/fossil-fuel-companies-underminingparis-agreement-negotiations-report. Acesso em: 6 set 2019.

STABINSKY, D. Agricultura climaticamente inteligente: problemas e mitos. Fundação Heinrich Böll, 18 set 2014. Disponível em: https://br.boell.org/pt-br/2014/09/18/agriculturaclimaticamente-inteligente-problemas-e-mitos. Acesso em: 6 set 2019.

SULLIVAN, R.; GOULDSON, A. Ten years of corporate action on climate change: What do we have to show for it? Elsevier BV, v.60, p.733-740, set 2013.

TABUCHI, H. "Vulnerable Voices" Lash Out as Companies Sway Climate Talks. The New York Times, 16 mai 2017.2 Disponível https://www.nytimes.com/2017/05/16/climate/corporations-global-climate-talks-bonn- 
VIEIRA, Clara Monteiro; TEIXEIRA, Ezequias Jagge; PINTO, João Roberto Lopes. A influência do setor corporativo nas discussões internacionais para o enfrentamento das mudanças climáticas.

germany.html. Acesso em: 6 set 2019.

UNCCD. The Conference of the Parties (COP). Disponível em: https://www.unccd.int/convention/conference-parties-cop. Acesso em: 6 set 2019.

UNFCCC. Admited NGOs. Disponível em: https://unfccc.int/process-and-meetings/partiesnon-party-stakeholders/non-party-stakeholders/admitted-ngos\#eq-3. Acesso em: 28 jun 2019a.

Statistics on non-Party stakeholders. Disponível em: https://unfccc.int/process-andmeetings/parties-non-party-stakeholders/non-party-stakeholders/statistics-on-non-partystakeholders\#eq-3. Acesso em: 6 set 2019b. 